The scientific community, one group with such vested interests, is now being forced by the political activism of the antivivisectionists to clamber out of its bunker and engage, at least with the easy questions, such as why animal experimentation cannot be banned outright. The Animal Research War is an important US step in the hitherto largely European process of making that simple case. But in the online era, the role of books is to provide accessible analysis of the details behind the sound bites, and this book should have gone further. For instance, Conn and Parker's research centre was infiltrated by an undercover animal-rights activist, and pictures of its apparently miserable primates are posted on PETA's website. Conn and Parker counter that the pictures were either doctored or taken deliberately just before cages were cleaned, or show behaviour seen naturally in the wild. So why not give visual proof? Why aren't we letting the cameras in?
Animal experimentation is a complex issue. Pretending otherwise, as Conn and Parker do, smacks of a cover-up. It is farcical to maintain that biomedical scientists are always angels, particularly if our best argument is that the US government has given us the all-clear to experiment. Let's be honest about past abuses and new cases that come to light, and move forward with case studies that show how animal research is run better these days. There may be mileage in animal-centred historical accounts being hurled at us by animal-rights campaigners, which Conn and Parker simply throw back with the rhetoric reversed. Is the correct lesson of thalidomide that animal testing is useless, or that insufficient animal testing is dangerous? Would the germ theory of disease still be conjecture without animal experimentation? Where would the polio vaccine be if Sabin and Salk had modern in vitro and in silico tools and twenty-first-century animal regulations? The undoubted cases of excessive and insufficient animal use, the dead ends and blind alleys, and the basic biology from whence it all came may be rich in honest detail, but such narratives and conjectures would make fascinating and persuasive reading.

The full story would also address the fundamental misunderstanding at the heart of the debate. Antivivisectionists maintain that researchers actively choose to experiment on animals, despite personal risk and bureaucratic hassles, to pursue science that is irrelevant to human or animal well-being. They also believe that our community conspires to keep the pointlessness of our profession from the public. Actually, our biggest problem is that we are poor at projecting the complex and messy process of science, and the humanity of scientists.

Andrew Read is professor of biology and entomology in the Center for Infectious Disease Dynamics, Pennsylvania State University, Pennsylvania 16802, USA.

\title{
Moralist, meet scientist
}

\section{Experiments in Ethics \\ by Kwame Anthony Appiah \\ Harvard University Press: 2008. 288 pp. \\ $\$ 22.95, £ 14.95$}

Picture a crowded room. In one corner, people are arguing about abortion; in another, about euthanasia. Around the coffee table, sitters dispute the obligations of the rich to the poor. By the sofa, folks are debating the criteria for a just war and the proper relations between men and women, and another group queries the use of primates in medical experiments. Nearby, a huddle of ethicists disputes politely which moral theory to accept - utilitarianism, kantianism, virtue ethics, contractarianism or something else. At the back, people are shouting something about whether suicide bombers are heroes or villains, and plates are flying. The individuals seem to have only one thing in common: each is convinced he is right.

A new guest arrives. Finding the front door unlocked, Science - not in the habit of knocking - has barged in on the pandemonic party. Will Science resolve the disputes and settle who is right? Will Science make us all look silly, showing we are squabbling over words that have no meaning? Or will Science remain aloof, like a nerdy stranger, observing the goings-on yet unable to address the rambunctious crowd?

In the past few decades, scientific interest in moral behaviour has surged. Psychologists, neuroscientists, evolutionary theorists and behavioural economists have begun to turn their experimental methods to understanding the ways we arrive at moral judgements. Scientists of human nature have called into question commonplaces about character and offered subversive explanations for various moral intuitions.

Philosopher Kwame Anthony Appiah explores the relation between empirical research into moral behaviour and moral philosophy, a discipline that questions what we ought to do and what there is reason to value. In Experiments in Ethics, he reviews a sample of the most intriguing experiments through which scientists have sought the mechanics of our moral minds.

Questionnaires have revealed that people's responses to moral dilemmas sometimes

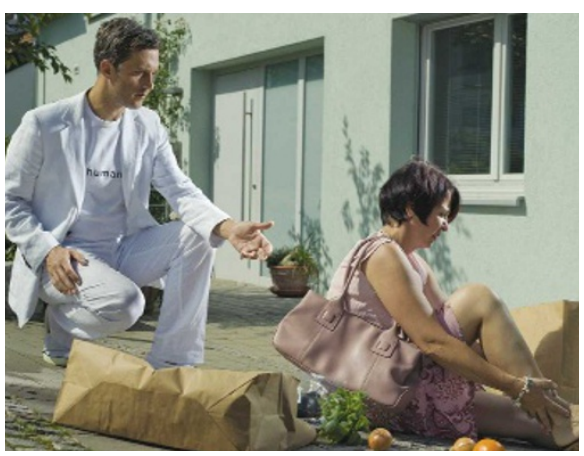

A passer-by is more likely to offer help if they have recently experienced good fortune. depend on how a problem is framed. This calls into question how much weight we can put on moral intuitions in cases in which superficial rewording makes us reverse our verdicts. Hypothetical problems in decision-making have demonstrated that general biases in human thinking arise when cognitive heuristics are applied outside their proper domains. Daniel Kahneman received the 2002 Nobel Prize in Economics for developing prospect theory, describing how people's behaviours deviate from the prescriptions of classical decision theory. Similar biases might occur in our moral thinking. In a famous study on moral judgement that used functional magnetic resonance imaging, Joshua Greene reported that utilitarian and non-utilitarian responses were associated with different neural signatures in moral 'up-close-and-personal' dilemmas.

In one philosophical thought experiment, a runaway trolley threatens to run over and kill five people. You can flick a switch that will deflect the trolley down a different track where it will kill one person. Most people say they would flick the switch - a response that is in accordance with utilitarianism, an ethical theory according to which the right action is the one that has the best net consequences.

Now consider a variation: again a trolley rolls along a track where it will kill five people. This time you are standing on a footbridge overlooking the track, and the only way you can save the five is by pushing a fat man standing beside you down on the track; if you do, the fat man will die, but his body mass will stop the trolley and five people will be saved. In this more personal version, most people say they would not push the fat man even though 
fewer people would die if they did.

Greene found that the brains of subjects who gave the non-utilitarian response - not to push the fat man - in this case showed increased activation in regions associated with emotion, whereas the brains of the rarer utilitarian responders were activated in areas associated with working memory and reasoning. This finding has been interpreted as support for utilitarianism, the theory supposedly reflective of more rational cognitive processes. Others dispute this. In a recent study by Michael Koenig and colleagues, patients with damage in brain areas involved in the normal generation of social emotions were more likely to select a utilitarian response. One can imagine ways of spinning this result that would be less flattering to the utilitarian.

Other investigations focus on behaviour. Dropping your papers outside a phone booth in a shopping mall, you are much more likely to get help from passers-by if they have just found money in the phone's coin-return slot, according to one study. Placing a coin in the slot increased the proportion of people who stopped to help, from almost nobody to almost everybody. You are also much more likely to get change for a note from a passer-by if standing near a fragrant bakery shop than outside a "neutral-smelling dry-goods store". Many studies have confirmed that morally irrelevant features have a strong effect on whether people offer help. Some have even concluded that character is a myth: it is the situation, rather than any stable personality trait, that determines whether one does the right thing. If true, this claim poses a big challenge to aristotelian ethics, which is built on the idea that we ought to cultivate a virtuous character. However, causes can be multifactorial: the fact that situational features often have a big influence does not imply that character never has any influence. It is probably a question of degree.

Psychologists have also sought to identify the basic 'taste buds' of our moral sensibilities. Jonathan Haidt of the University of Virginia, Charlottesville, proposes we have a limited number of distinct moral modules, which get activated in response to different kinds of moral problems. Haidt's taxonomy distinguishes responses related to harm, fairness and reciprocity, hierarchy and respect, purity and pollution, in-group and out-group boundaries, and awe and elevation. If we do have all these sensibilities, one might suspect that moral theories that recognize or privilege only one or two of them are unduly restricted.

Experiments in Ethics is erudite, concise and engagingly written. Appiah assesses that experimental science is relevant to the enterprise of normative ethics, and that the relation between the two, although complex, need not be antagonistic. Returning to my analogy, Appiah recommends that our labcoated gatecrasher enter into a dialogue with the party-goers, and that they should welcome Science into their midst. The nine
Muses of music and the arts should also be invited. Seeing the central issue of ethics as eudemonia, the good life, Appiah believes that such a plenary gathering will best enable both its study and its achievement.

Nick Bostrom is director of the Future of Humanity Institute, Faculty of Philosophy and the James Martin 21st Century School, University of Oxford, Oxford OX14JJ, UK.

\section{Music grown from garden weeds}

\section{Umbel Ballits: Dylan Martorell \\ Craft Victoria, Melbourne \\ Until 28 June}

Botany, traditionally the preserve of watercolourists with a meticulous eye for detail, continues to inspire contemporary artists. Graphic designer and musician Dylan Martorell uses plant morphology as a starting point to create sound sculptures. His latest work is now on show in Melbourne, Australia.

Martorell begins by drawing plant-growth algorithms in pencil or ink on paper. Based on patterns he discerns in botanical structures, he uses a visual notation that enables the diagrams to function as musical scores. For this exhibition, he sourced plant structures from an Australian botanical manual by David Whibley and Trevor Christensen called Garden Weeds - Identification and Control (Botanic Gardens of Adelaide, 1991).

Moving beyond his precise drawings, Martorell also constructs less ordered three-dimensional sculptures. Evoking the original botanical structures, he incorporates found objects, musical instruments and living plants. He also digitally converts data from his drawings into music that slides from one frequency to another. Selections of the resulting 3.5minute sound tracks are played simultaneously in Craft Victoria's gallery, generating complex, overlapping sound patterns that create a fourth, aural dimension to his multimedia interpretation of the plant world. A small ensemble of musicians, including Martorell, occasionally rehearses and performs live music in the gallery, using the sculptures as instruments to generate sound.

"Currently I am creating hand-written scores based on the floral structures in various flowering plants such as racemes [unbranched flowers] and umbels [umbrella-like flowers]," says Martorell. Although the title of his exhibition - Umbel Ballits - mimics linnaean binomial classification, that was not his main intention. "Ballits is old Afro-American vernacular for ballads," he explains. "The sound pieces in my exhibition are based on pentatonic tunings, which were influenced by a variety of musical traditions, including the development of blues music in its journey from Africa to America."

The artist's musical scores take two forms. In one, he uses an upright trunk or stem to represent the base note or drone of the music, with branches or clusters providing extra musical notation. Scales and frequencies are represented on the horizontal axis and time is represented vertically. His second score pattern is shaped like a flower, with each petal representing a different base note, either played in clockwise succession or simultaneously. Using structures derived from local flora as his building blocks, Martorell draws, sculpts and composes multilayered and locationspecific artworks that challenge our perception of botanical art. Colin Martin is a writer based in London. 